\title{
Mucosa-Associated Lymphoid-Tissue Lymphoma of the Descending Colon in a Patient with Blastocystis hominis Infection: A Case Report and Review of Literature
}

\author{
Silvia Martín-Batista ${ }^{1}$, Sunil Lakhwani ${ }^{1,2 *}$, Patricia Machado-Machado ${ }^{1}$, María José Rodríguez-Salazarl, Miguel T. \\ Hernández ${ }^{1,2}$ and José María Raya-Sánchez ${ }^{1,2}$ \\ ${ }^{1}$ Hematology Department, Hospital Universitario de Canarias, La Laguna, Tenerife, Spain \\ ${ }^{2}$ Internal Medicine Department, La Laguna University, Tenerife, Spain
}

\begin{tabular}{l} 
A R T I C L E I N F O \\
\hline Article history: \\
Received: 13 August, 2020 \\
Accepted: 26 August, 2020 \\
Published: 30 September, 2020 \\
\hline Keywords: \\
MALT lymphoma \\
gastrointestinal cancer \\
Blastocystis hominis
\end{tabular}

\begin{abstract}
A B S T R A C T
Mucosa-associated lymphoid tissue (MALT) lymphoma is an extra nodal marginal zone B-cell lymphoma that has been associated with chronic infections. It affects especially stomach, but other organs of gastrointestinal tract can be also involved. Colon MALT lymphoma is a very rare disease. We report a case of large bowel MALT lymphoma diagnosed as a result of weight loss and positive occult fecal blood test. Blastocystis hominis infection was detected in fecal analysis. We hypothesize chronic parasitic infection could be related with the development of the lymphoma.
\end{abstract}

C 2020 Sunil Lakhwani. Hosting by Science Repository.

\section{Introduction}

Mucosa-associated lymphoid tissue (MALT) lymphoma is an extra nodal marginal zone B-cell lymphoma that represents approximately $8 \%$ of all non-Hodgkin's lymphomas $[1,2]$. It shows a remarkably indolent disease course with a median survival of more than 12 years [3]. Different organs can be affected by this disease like lungs, ocular adnexa, thyroid, salivary glands, or skin, but the most common location is stomach $(70 \%)$ [3]. It can also develop at other organs of the gastrointestinal (GI) tract such as the small intestine or less frequently large bowel. It occurs mainly in the sixth decade of life with no differences between genders [4].

MALT lymphoma is characterized for its association with infections and autoimmune diseases. Among the most related microorganisms, Helicobacter pylori, Campylobacter jejuni and Chlamydia psittaci are usually associated with gastric, small bowel and ocular adnexal MALT lymphoma respectively [2]. As autoimmune diseases, Hashimoto thyroiditis is associated with thyroid involvement and Sjögren's syndrome is associated with salivary glands affectation [3]. It seems that chronic immune response driven by infection or autoimmunity plays an important role in the development of the disease. Nevertheless, more steps are necessary to reach to the development of the lymphoma.

Regarding genetic alterations, the main oncogene involved in this disease is MALT1, which is located at long arm of chromosome 18 (18q21) [5]. MALT1 protein is a protease involved in different functions, among others the activation of nuclear factor kappa B (NF$\kappa B)$. Structural alterations that affect this gene are $\mathrm{t}(11 ; 18)(\mathrm{q} 21 ; \mathrm{q} 21)$, $\mathrm{t}(14 ; 18)$ (q32; q21) and trisomy 18 [6]. Another oncogene implicated in the disease is BCL10, located at chromosome 1p22 and overexpressed when $\mathrm{t}(1 ; 14)(\mathrm{p} 22 ; \mathrm{q} 32)$ is present. Both ways lead to activation of NF$\kappa \mathrm{B}$ signaling which seems to be an important oncogenic event in this disease. Other recurrent chromosomic alterations are trisomy 3 and $t$ (3; 14) (q27; q32) [2, 3]. In this paper, we present a patient with MALT lymphoma in a colonic polyp with detection of Blastocystis hominis in stool test.

*Correspondence to: Sunil Lakhwani, Hematology Department, Hospital Universitario de Canarias, La Laguna, Internal Medicine Department, La Laguna University, Tenerife, Spain; E-mail: sunillakhwani@hotmail.com 


\section{Case Report}

A 62-year-old man with a medical history of bronchial asthma, arterial hypertension and prostate cancer treated by prostatectomy nine years before, visited his doctor referring loss of $10 \mathrm{~kg}$ weight in the last year and no other symptoms. The following tests were performed:

i. Blood evaluation revealed hemoglobin $14.9 \mathrm{~g} / \mathrm{dL}$, white blood cells 7.000/mm3 (neutrophil, lymphocyte and monocyte in normal range and eosinophil 1.100/mm3), platelets 247.000/mm3. Biochemistry and immunoglobulins levels were normal.

ii. The serologies of hepatitis $\mathrm{B}$ and $\mathrm{C}$ viruses and HIV were negative.

iii. Stool detection of Helicobacter pylori (HP) antigen was negative as well as stool culture. Fecal test for parasite detection revealed that Blastocystis hominis was present.

iv. Fecal occult blood test was positive.

A colonoscopy was done, and 3 polyps were founded in the large bowel (Figures 1A \& 1B). The biopsies were stained with hematoxylin and eosin and in two of the three sections, tubular polyps were described. The third one showed a histopathological picture compatible with MALT lymphoma (Figures 2A, 2B, 2C \& 2D). The whole lesion was removed. Immunohistochemistry profile (CD20+, CD3-, BCL2+, CD43+, BCL6-, CD5-, CD10-, CD23- and cyclin D1-) and FISH (rearrangement of 18q21 evaluated by break-apart probe) was accorded to the diagnosis. Bone marrow trephine biopsy did not show infiltration or abnormal findings, and TC body scan was normal.
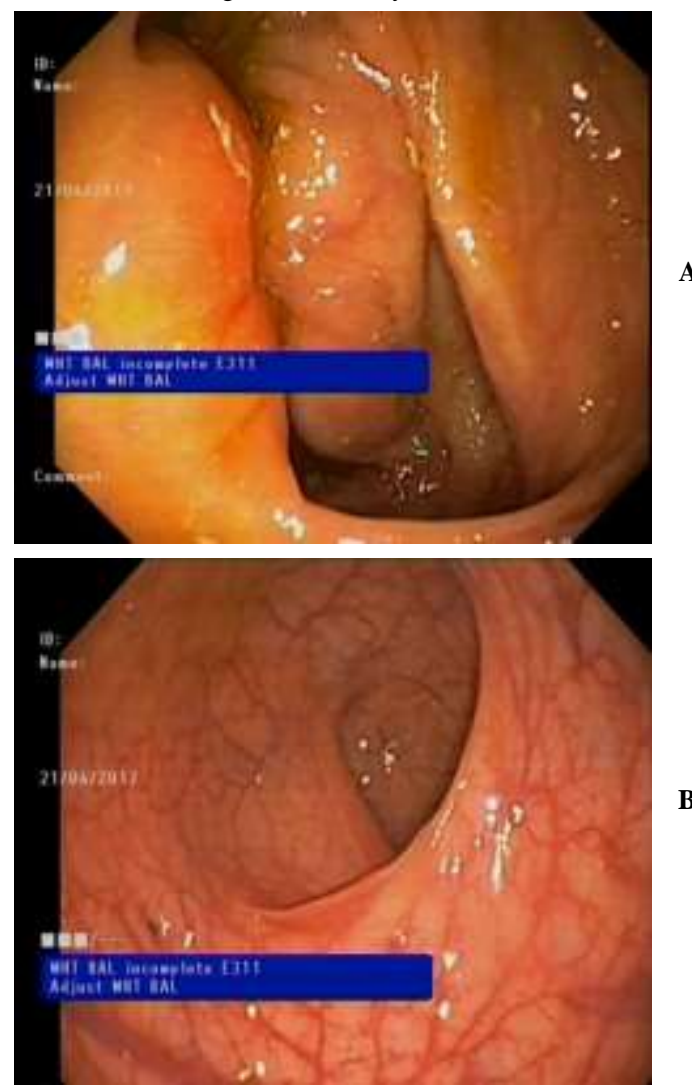

Figure 1: A) \& B) Tissue of polypoid appearance, $44 \mathrm{~cm}$ from the anal margin.

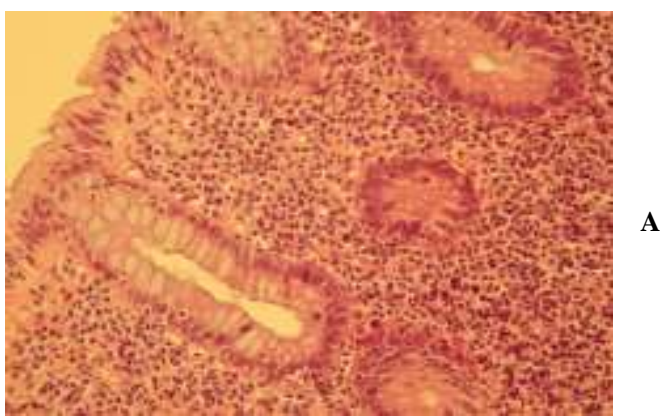

A
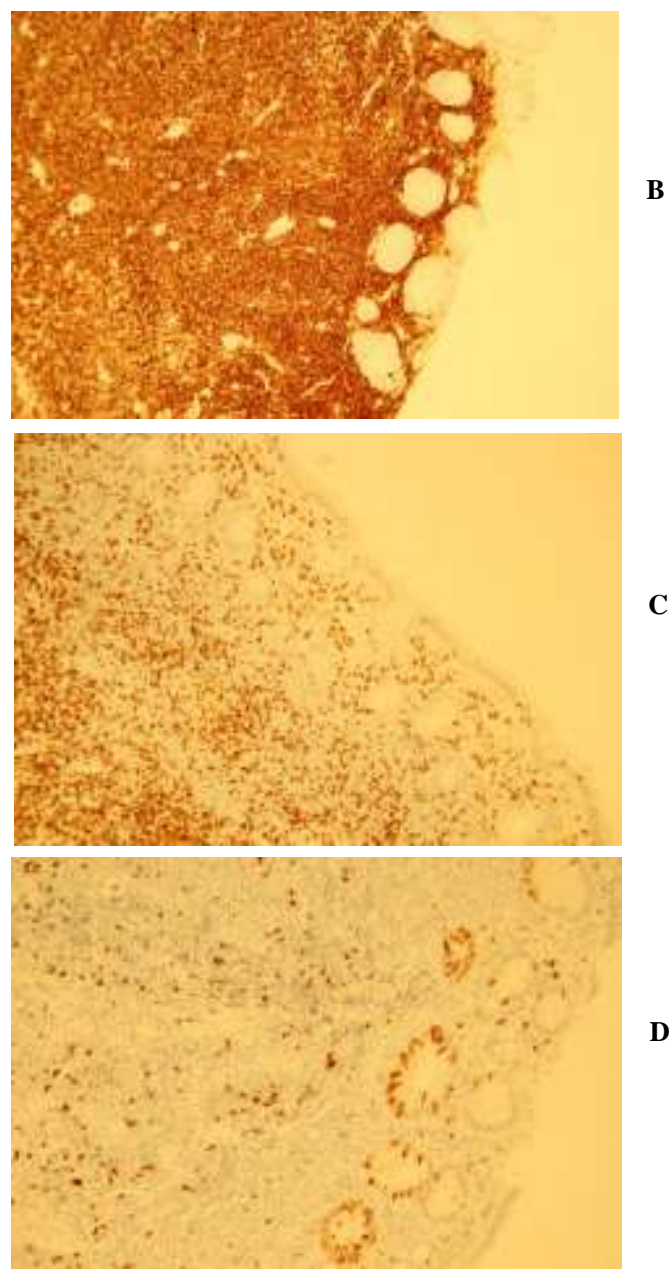

Figure 2: Biopsy of colon showing proliferation of atypical lymphoid cells involving the colonic mucosa and submucosa, forming a diffuse infiltrate: A) Lymphoid cells are small in size and have scant to moderate cytoplasm (Hematoxylin-eosin $x 40$ ) B) With CD20 it is shown that the lymphoma is of B strain (CD20, x25) C) The presence of T lymphocytes is much less apparent (CD3, x25) D) Staining for Ki-67 shows the low proliferative capacity of this type of lymphomas, and how is more marked in the cells of the glandular ducts themselves (Ki-67, x25).

In view of the finding of Blastocystis hominis infection, we treated the patient with metronidazole for 10 days. We continued the follow up without specific treatment. Three months later another colonoscopy and a gastroscopy were done, as well as a new parasites study in stool. The results were as follows: 
i. Colonoscopy revealed no evidence of MALT lymphoma lesions, and two new polyps were removed and resulted in tubular adenoma.

ii. Gastroscopy showed Barret esophagus as single finding and $H$. pylori test was negative.

iii. Stool test for parasitic infection was now negative.

At eight months from the diagnosis, the patient remains asymptomatic and he has recovered his usual weight. Eosinophilia persists in spite of treating the Blastocystis hominis, but we assume it is secondary to his bronchial asthma.

\section{Discussion}

MALT lymphoma of the colon is a rare disease and comprises only $2.5 \%$ of MALT lymphomas and $4 \%$ approximately of all GI non-Hodgkin lymphoma [4]. Although, MALT lymphoma is frequently associated with chronic infections or autoimmune diseases, no cause for the colonic location have been described so far.

Blastocystis hominis is a worldwide distributed protozoan which can cause intestinal infection. The prevalence seems to be higher in developing countries than in developed countries. Most of the infected patients are asymptomatic, but sometimes infection can produce acute or chronic diarrhea, flatulence, abdominal cramps, or other GI symptoms [7]. This chronic infection can produce an intestinal light chronic inflammation similar to that produced by H. pylori at stomach [6]. The coincidental finding of a colonic MALT lymphoma and intestinal infection by Blastocystis hominis in this case leads us to think that chronic infection can be the cause of the neoplastic disease.

Table 1: Summary of most recommended treatments options in GI tract MALT lymphomas.

\begin{tabular}{|c|c|c|c|c|}
\hline Location & Frequency & HP infection & Treatment & Comments \\
\hline Esophagus & $<1 \%$ & NEA & $\begin{array}{l}\geq 3 \mathrm{~cm}: \mathrm{SR} \\
<3 \mathrm{~cm}: \mathrm{ER}\end{array}$ & Usually Cht or Rt is added [8] \\
\hline Stomach & $60 \%$ & $\begin{array}{l}\mathrm{EI} / \mathrm{NI} \\
\mathrm{NI}\end{array}$ & $\begin{array}{l}\text { L: HPE. If relapse or not } \\
\text { respond: Rt (best results) [4] [9] } \\
+/- \text { Cht }+/-\mathrm{Sg} \\
\text { D: Cht based on R } \\
\mathrm{L} \text { and low grade: Rt (the best } \\
\text { results) }\end{array}$ & $\begin{array}{l}\text { Ab regimen should be based on epidemiology } \\
\text { and resistances. t(11;18)/API2-MALT1 is } \\
\text { associated with resistance to Ab.[10] } \\
\text { No agreement about Rt in these cases } \\
\text { Usually } 30-40 \text { Gy [9] } \\
\text { Cht in study, at this date, best results with } \mathrm{R} \\
+\mathrm{Bd} / \mathrm{Cl} / \mathrm{Fl}\end{array}$ \\
\hline \multirow[t]{3}{*}{ Small bowel } & $30 \%$ & $\begin{array}{l}\text { Campylobacter jejuni } \\
\text { EI }\end{array}$ & $\mathrm{Ab}$ régimen $[11]$ & $\begin{array}{l}\text { Tetracycline or metronidazole and ampicillin } \\
\text { at least } 6 \text { months }\end{array}$ \\
\hline & & NI & $\begin{array}{l}\mathrm{L}: \mathrm{SR} / \mathrm{ER} \\
\mathrm{Rt}\end{array}$ & FLT \\
\hline & & & $\mathrm{D}$ : Cht based on $\mathrm{R}$ or $\mathrm{Cl}$ & $\begin{array}{l}\text { Usually } \mathrm{R}-\mathrm{CHOP} \\
\text { In study: } \mathrm{R}+\mathrm{Cl} / \mathrm{Fl}\end{array}$ \\
\hline Large bowel & $2.5 \%$ & & & \\
\hline - Cecum and rectum & & NEA & $\begin{array}{l}\text { L: SR/ER } \\
\text { D: Cht based on R } \\
\quad \text { Rt good responses }\end{array}$ & $\begin{array}{l}\text { Some cases responses at HPE (even } \\
\text { negative). One case published of relapse after } \\
1 \text { year who received levofloxacin } 14 \text { days. }\end{array}$ \\
\hline \multirow[t]{2}{*}{ - Sigmoid colon } & & & & FLT [4] \\
\hline & & NEA & $\begin{array}{l}\text { L: SR/ER } \\
\text { D: Cht based on R }\end{array}$ & $\begin{array}{l}\text { Rt before resection to dismal the lesion is also } \\
\text { an option } \\
\text { Usually R-CHOP +/- Rt [4] } \\
\mathrm{R} \text { in monotherapy is being studied [4] }\end{array}$ \\
\hline
\end{tabular}

NEA: No Evidence of Association; EI: Evidence of Infection; NI: No Evidence of Infection; L: Localized; D: Disseminated; SR: Surgical Resection; ER: Endoscopic Resection S; Cht: Chemotherapy; Rt: Radiotherapy; Sg: Surgery; HP: Helycobacter pylori; HPE: HP Eradication; Ab: Antibiotics; FLT: First Line Treatment; HPE: Helicobacter pylori Eradication; R- CHOP: Rituximab Cyclophosphamide Hydroxydaunomycin Oncovin Prednisolone; R: Rituximab; Cl: Clorambucil; Bd: Bendamustine; Fl: Fludarabine.

Different treatment options have been proposed for gastrointestinal MALT lymphoma which are summarized at (Table 1). Treatment changes depending on the location, the size, if it is localized or disseminated and if an infection is present [8-14]. About colonic MALT lymphoma, if it is localized, as our case, resection (surgical or endoscopic) seems to be the best treatment option. Some cases located at cecum or rectum could obtain response after treating $H$. pylori. For disseminated disease immunochemotherapy including rituximab seems to be the best treatment option, adding sometimes radiotherapy. In our case we performed endoscopic resection of the tumor and treatment of the chronic infection. Blastocystis hominis treatment is sometimes unsatisfactory because infection persists [7]. In the case of our patient, the infection seems to have been solved with oral metronidazole. 


\section{Conclusion}

We have found a possible etiological association between Blastocystis hominis infection and colonic MALT lymphoma. As far as we know, no previous report of this association has been published. According to bibliography, resection of the tumor and treatment of the infection when presents, seems to be the best treatment option for localized colon disease.

\section{REFERENCES}

1. Catherine Thieblemont, Emanuele Zucca (2017) Clinical aspects and therapy of gastrointestinal MALT lymphoma. Best Pract Res Clin Haematol 30: 109-117. [Crossref]

2. Katharina Troppan, Kerstin Wenzl, Peter Neumeister, Alexander Deutsch (2015) Molecular Pathogenesis of MALT Lymphoma. Gastroenterol Res Pract 2015: 102656. [Crossref]

3. Max I Schreuder, Michiel van den Brand, Konnie M Hebeda, Patricia J T A Groenen, J Han van Krieken et al. (2017) Novel developments in the pathogenesis and diagnosis of extranodal marginal zone lymphoma. J Hematop 10: 91-107. [Crossref]

4. Hafsa Abbas, Masooma Niazi, Jasbir Makker (2017) MucosaAssociated Lymphoid Tissue (MALT) Lymphoma of the Colon: A Case Report and a Literature Review. Am J Case Rep 18: 491-497. [Crossref]

5. Qiang Ma, Chun Zhang, San'gao Fang, Peng Zhong, Xiangfeng Zhu et al. (2017) Primary esophageal mucosa-associated lymphoid tissue lymphoma. A case report and review of literature. Medicine 96: e6478. [Crossref]

6. Pedro Farinha, Randy D Gascoyne (2005) Molecular Pathogenesis of Mucosa-Associated Lymphoid Tissue Lymphoma. J Clin Oncol 23: 6370-6378. [Crossref]
7. Gerald L Mandell, John E Bennett, Raphael Dolin (2010) Principles and practice of Infectious Diseases Seventh edition. Churchill Livingstone 3561-3568.

8. Myung Jin Nam, Byung Chang Kim, Sung Chan Park, Chang Won Hong, Kyung Su Han et al. (2017) Mucosa-Associated LymphoidTissue Lymphoma of the Cecum and Rectum: A Case Report. Ann Coloproctol 33: 35-38. [Crossref]

9. Berthe M P Aleman, Rick L M Haas, Richard W M van der Maazen (2010) Role of radiotherapy in the treatment of lymphomas of the gastrointestinal tract. Best Pract Res Clin Gastroenterol 24: 27-34. [Crossref]

10. Ming Qing Du (2017) MALT lymphoma: Genetic abnormalities, immunological stimulation and molecular mechanism. Best Pract Res Clin Haematol 30: 13-23. [Crossref]

11. Rajiv Bhuta, Michael Bromberg, Ashish Bains, Ron Schey (2016) Mucosa-Associated Lymphoid Tissue Lymphoma of the Sigmoid Colon Discovered on Routine Screening Colonoscopy in Patient with Hepatitis C and Helicobacter pylori Infection. ACG Case Rep J 3: e90. [Crossref]

12. Estella Matutes, Carlos Montalban (2017) Clinical features and management of non-gastrointestinal non-ocular extranodal mucosa associated lymphoid tissue (ENMALT) marginal zone lymphomas. Best Pract Res Clin Haematol 30: 99-108. [Crossref]

13. Sermin Borekci, Murat Ozbalak, Ezel Ersen, Hilal Ak1, Muhlis Cem Ar et al. (2017) Bronchus Associated Lymphoid Tissue Lymphoma Presenting with Immunodeficiency and Multiple Pulmonary Nodules. Case Rep Pulmonol 2017: 4804378. [Crossref]

14. Yin Liu, Yinyan Tangsun, Yonglong Xiao, Deping Zhang, Min Cao (2016) Pulmonary infiltration with eosinophilia complicated with mucosa-associated lymphoid tissue lymphoma: A case report. Oncol Lett 12: 1818-1820. [Crossref] 